\title{
Analysis of a PWM Converter with Less Current Ripple, Wide Voltage Operation and Zero-Voltage Switching
}

\author{
Bor-Ren Lin * and Yi-Hao Peng
}

check for updates

Citation: Lin, B.-R.; Peng, Y.-H. Analysis of a PWM Converter with Less Current Ripple, Wide Voltage Operation and Zero-Voltage Switching. Processes 2021, 9, 580. https://doi.org/10.3390/pr9040580

Academic Editors: Masoud Soroush, Chang-Hua Lin and Jahangir Hossain

Received: 19 February 2021

Accepted: 23 March 2021

Published: 26 March 2021

Publisher's Note: MDPI stays neutral with regard to jurisdictional claims in published maps and institutional affiliations.

Copyright: (c) 2021 by the authors. Licensee MDPI, Basel, Switzerland. This article is an open access article distributed under the terms and conditions of the Creative Commons Attribution (CC BY) license (https:/ / creativecommons.org/licenses/by/ $4.0 /)$.
Department of Electrical Engineering, National Yunlin University of Science and Technology, Yunlin 640, Taiwan; m10912001@yuntech.edu.tw

* Correspondence: linbr@yuntech.edu.tw

\begin{abstract}
This paper studies and implements a power converter to have less current ripple output and wide voltage input operation. A three-leg converter with different primary turns is presented on its high-voltage side to extend the input voltage range. The current doubler rectification circuit is adopted on the output side to have low current ripple capability. From the switching states of the three-leg converter, the presented circuit has two equivalent sub-circuits under different input voltage ranges $\left(V_{\text {in }}=120-270 \mathrm{~V}\right.$ or $\left.270-600 \mathrm{~V}\right)$. The general phase-shift pulse-width modulation is employed to control the presented converter so that power devices can be turned on at zero voltage in order to reduce switching loss. Compared to two-stage circuit topologies with a wide voltage input operation, the presented converter has the benefits of simple circuit structure, easy control algorithm using a general integrated circuit or digital controller, and less components. The performance of the presented circuit is confirmed and validated by an $800 \mathrm{~W}$ laboratory prototype.
\end{abstract}

Keywords: PWM converter; soft switching; less current ripple

\section{Introduction}

For the past decade, clean energy sources have brought attention to the depletion of fossil fuel demand due to the rising demand for electric power. Fuel cell stacks, wind energy, and photovoltaic (PV) are the most attractive renewable energy sources [1-6]. However, the output voltage of dc wind power and PV panels is unstable and widely varies. High-frequency dc-link converters can convert an unstable dc voltage to a constant dc voltage by using duty cycle control [7-9] or pulse frequency modulation (PFM) [10-12]. In duty cycle control, the turn-on time of the power switch is related to input voltage under the constantly switching frequency. Therefore, the load terminal is regulated at the command voltage. In the PFM approach, the switching frequency is variable and related to input voltage. Thus, the input impedance of the resonant tank is variable to change voltage gain and regulate load voltage. For dc wind energy and PV power, the solar intensity and wind speed have a wide deviation. Therefore, the output voltage of PV panels and wind generators is variable in a wide voltage range. In conventional isolated dc converters, the maximum and minimum effective duty cycles are related to input voltage, $d_{\text {eff, } \max } / d_{\text {eff, } \min }=$ $V_{\text {in, } \max } / V_{\text {in,min }}$. In phase-shift pulse-width modulation (PWM) converters, the maximum (or minimum) effective duty cycle or duty ratio is normally less (or greater) than 0.45 (or 0.15 ). Then, the available input voltage variation range $V_{i n, \max } / V_{\text {in, min }}$ is less than 3 . However, the output voltage variation of some dc wind power and PV panels may be greater than 4. To overcome this problem, dc converters with a cascaded structure [13-15] have been studied which have a wide input voltage variation. The problem with the cascaded structure converters is low efficiency. The dc converters with duty cycle control were studied in [16-18] to achieve wide voltage operation and low switching loss. However, the control algorithm is too complicated for using a general-purpose integrated circuit. Full-bridge converters with wide input voltage range that have PWM or PFM schemes have been presented in $[19,20]$. The input voltage variation range in [20] with two transformers 
and one ac switch structure could achieve $V_{i n, \max } / V_{\text {in, } \min }=4$. Four equivalent circuits could be operated in [14] to realize wide voltage operation. However, the control scheme is more complicated when using a general-purpose integrated circuit. In [21], a hybrid dc-dc converter is presented to have wide voltage operation between $V_{\text {in }}=120 \mathrm{~V}$ and $600 \mathrm{~V}$. However, this converter has more ripple current on the output inductor and more passive components on the secondary side. In [22], a wide voltage resonant converter was discussed and implemented to be operated between $V_{\text {in }}=10 \mathrm{~V}$ and $160 \mathrm{~V}$ for low-power applications. However, the circuit topology was still a cascaded dc-dc converter.

In the present work, a three-leg structure phase-shift PWM converter is studied and implemented to have a wide voltage input operation and a wide load range of zero-voltage turn-on operation. Two sub-circuits with different voltage gains can be operated in the presented converter according to input voltage ranges. Hence, the presented converter can accomplish wide input voltage operation. The phase-shift PWM approach is used to control the gating signals of power devices. Then, the zero-voltage switching (ZVS) operation for the three-leg converter can be easily achieved. The current doubler rectification circuit is operated on the load terminal. Therefore, the current ripple on the output terminal is decreased. A Schmitt voltage comparator is used in the control circuit to select the proper sub-circuit, having a high voltage gain under a low voltage input range or a low voltage gain under ahigh voltage input range. The reference voltage of the voltage comparator is equal to $270 \mathrm{~V}$. The presented circuit is designed to be operated under $V_{\text {in }}$ $=120 \sim 600 \mathrm{~V}$. Compared to the conventional cascaded structure converter in [13-18], the studied converter has an easy control algorithm and a simple circuit structure. Compared to conventional converters with a wide voltage operation [19-22], the proposed converter has fewer active switches and a wider voltage deviation region. The effectiveness and benefits of the presented circuit are verified by theoretical analysis and experimental verifications with an $800 \mathrm{~W}$ prototype.

\section{Proposed Converter}

Figure 1a gives the circuit schematic of the presented converter. It can be observed that the three-leg circuit structure is operated on the primary side and a current doubler rectification structure is adopted on the secondary side. An isolation transformer with two sets of primary-turn $n_{p}$ and one set of secondary-turn $n_{s}$ is selected in the converter. The ac switch $Q$ is realized by two power MOSFETs (Metal-Oxide-Semiconductor FieldEffect Transistors) with a back-to-back connection. According to low voltage or high voltage input conditions, $Q$ is controlled to be OFF or ON. Therefore, two equivalent sub-circuits are worked in the presented converter. For a low voltage input region (e.g., $\left.V_{\text {in }, L}=V_{\text {in,min }} \sim 2.3 V_{\text {in,min }}\right), Q, S_{1}$, and $S_{2}$ are OFF, and the two-leg PWM converter shown in Figure $1 \mathrm{~b}$ with active switches $S_{3}-S_{6}$ is operated to regulate the load voltage. The duty cycle control is selected to generate the necessary gate signals of active switches $S_{3}-S_{6}$. Thus, the ZVS operation of $S_{3}-S_{6}$ is achieved. The output voltage can be estimated as $V_{o}=n_{s} V_{i n, L} d_{e f f} / n_{p}-V_{D}$, where $d_{e f f}$ is an effective duty cycle and $V_{D}$ is the voltage drop on $D_{1}$ or $D_{2}$. The output voltage can be kept stable and constant by the regulation of the effective duty ratio $d_{e f f}$. The minimum effective duty ratio $d_{\text {min,min }}$ happens at the maximum input voltage case $V_{i n, L, \max }$ under the low voltage input range. On the other hand, the minimum input voltage $V_{i n, L, \min }$ will result in the maximum effective duty ratio $d_{e f f, \max }$ when the converter is operated in the low voltage input range. The voltage gain of the converter in the low voltage input range is $G_{d c-L}=V_{o} / V_{i n, L} \approx d_{e f f} / N_{L}$, where $N_{L}=n_{p} / n_{\mathrm{s}}$. For the high voltage input region (e.g., $V_{i n, H}=2.3 V_{i n, \min } \sim 5 V_{i n, \min }$ ), $Q$ is $\mathrm{ON}$ and $S_{3}$ and $S_{4}$ are OFF. The two-leg PWM converter shown in Figure 1c with active switches $S_{1}, S_{2}, S_{5}$, and $S_{6}$ is operated to regulate the output voltage. $S_{1}$ and $S_{2}\left(S_{5}\right.$ and $\left.S_{6}\right)$ are active devices on the leading leg (lagging leg) of the phase-shift PWM converter. As can be noted in Figure 1c, the transformer turns ratio is $N_{H}=2 n_{p} / n_{\mathrm{s}}$ instead of $n_{p} / n_{\mathrm{s}}$. Under the high voltage input condition, the output voltage is expressed as $V_{o}=n_{s} V_{i n, H} d_{e f f} /\left(2 n_{p}\right)-V_{D}$ and the voltage gain becomes $G_{d c-H}=V_{o} / V_{i n, H} \approx d_{e f f} / N_{H}$. From the circuit operation 
in the previous statements, the presented circuit can achieve ZVS operation and a wide voltage input operation with about $V_{i n, \min }-5 V_{i n, \min }$ input voltage variation by the proper switching of $Q$ and $S_{1}-S_{6}$.

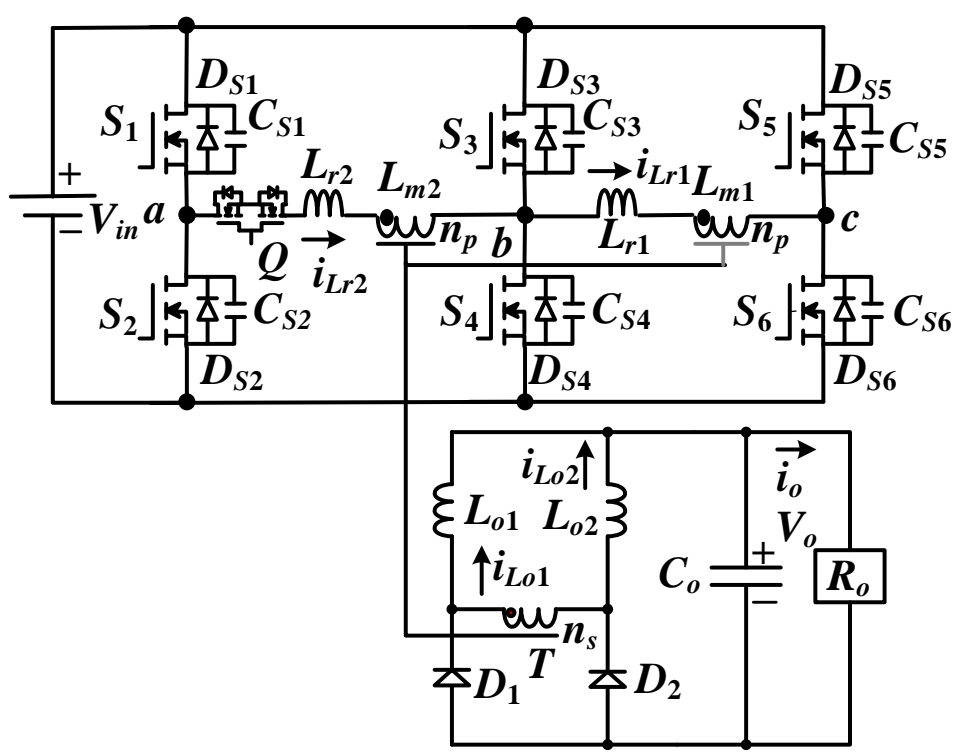

(a)

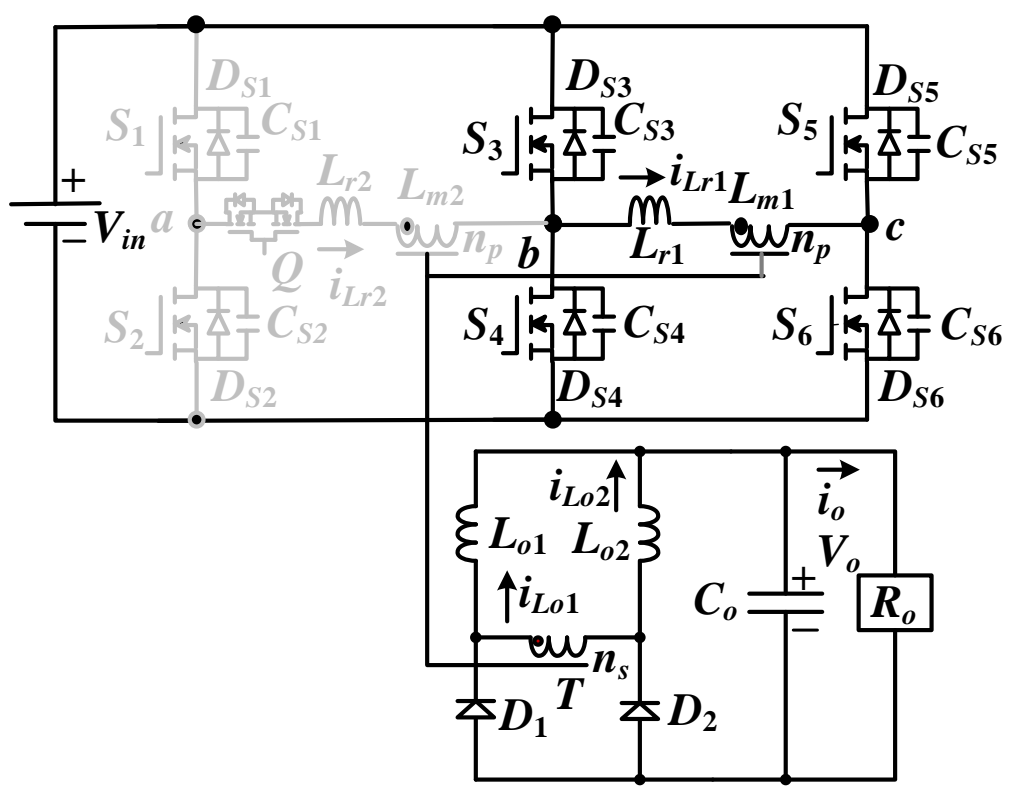

(b)

Figure 1. Cont. 


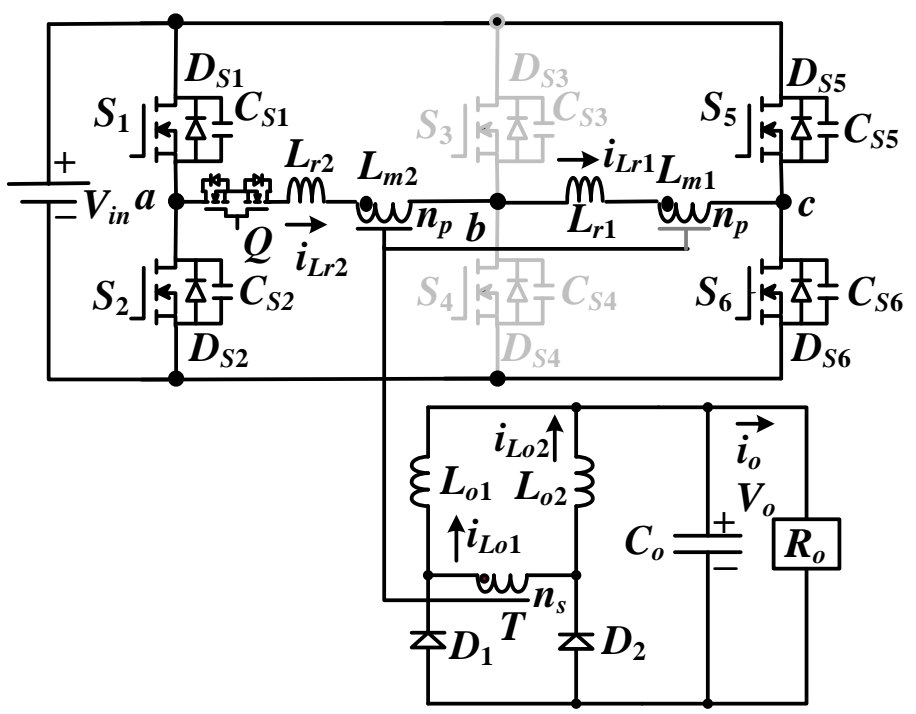

(c)

Figure 1. Proposed converter (a); circuit schematic (b); equivalent sub-circuit under low voltage input range (c); equivalent sub-circuit under high voltage input range.

\section{Principle of Operation}

The converter has two sub-circuits shown in Figure $1 \mathrm{~b}, \mathrm{c}$ for low voltage input $V_{\text {in }, L}$ and high voltage input $V_{i n, H}$ operations. For the low voltage input region $\left(V_{i n, \min } \leq V_{i n, L}<\right.$ $\left.2.3 V_{\text {in,min }}\right)$ in Figure $1 \mathrm{~b}, Q, S_{2}$ and $S_{1}$ are turned OFF and $S_{3}-S_{6}$ are active with duty cycle control. The transformer turns ratio is $N_{L}=n_{p} / n_{s}$. The corresponding PWM waveforms are provided in Figure 2a. For the high voltage input region $\left(2.3 V_{i n, \min } \leq V_{i n, H}<5 V_{i n, \min }\right)$ in Figure 1c, $Q$ is ON and $S_{3}$ and $S_{4}$ are OFF. $S_{1}, S_{2}, S_{5}$, and $S_{6}$ are active with duty cycle control. The transformer turns ratio is $N_{H}=2 n_{p} / n_{s}$. It is assumed the magnetizing inductances $L_{m 1}=L_{m 2}=L_{m}>L_{r 1}=L_{r 2}=L_{r}$ and the output capacitances $C_{S 1}=\ldots=C_{S 6}=$ $C_{o s s}$. The PWM waveforms under the high voltage input condition are given in Figure $2 \mathrm{~b}$.

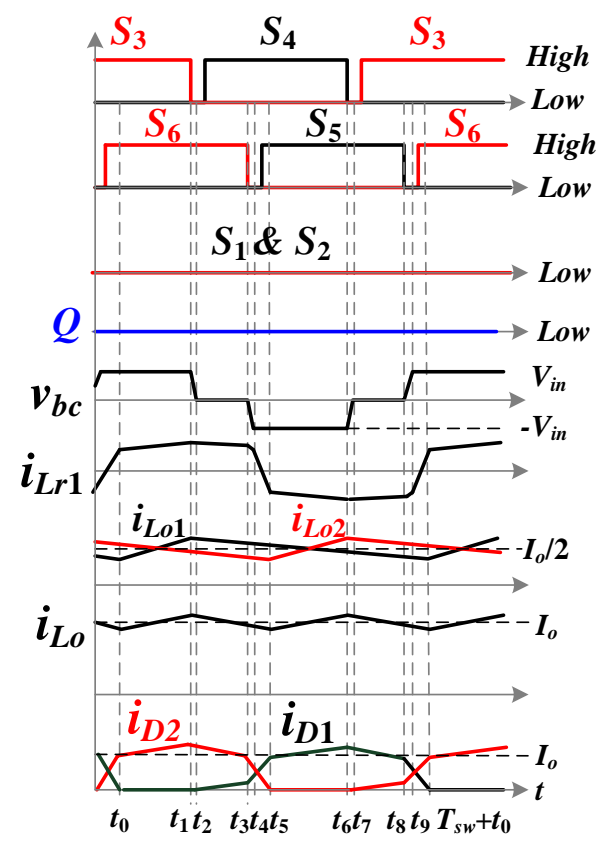

(a)

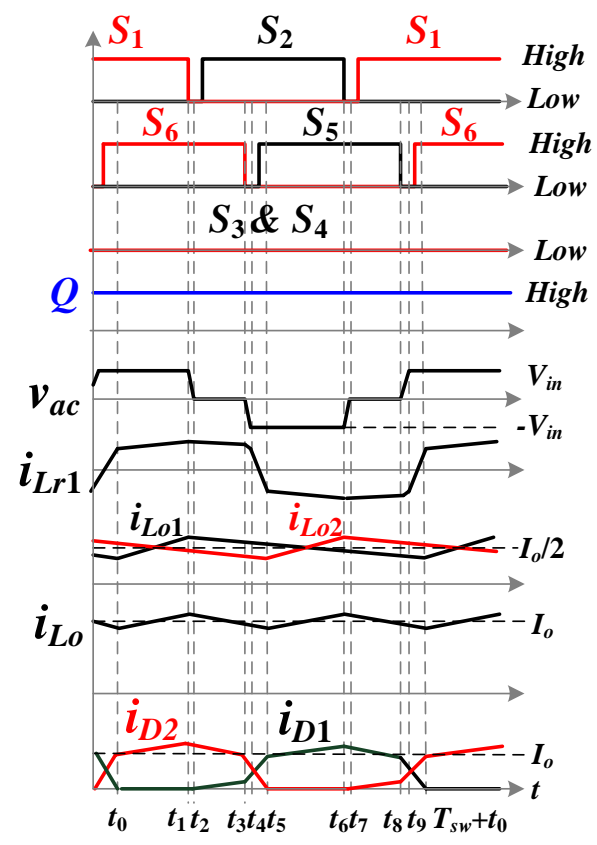

(b)

Figure 2. Pulse-width modulation (PWM) singles in the (a) low voltage input range; (b) high voltage input range. 
According to the PWM waveforms of $S_{3}-S_{6}$ and the conducting states of $D_{1}$ and $D_{2}$, ten operating steps can be observed in Figure 2a under the low voltage input case. As can be observed, the PWM waveforms are symmetric for each half cycle. Thus, only the first five operating steps are explained briefly, and the corresponding step circuits are given in Figure 3.

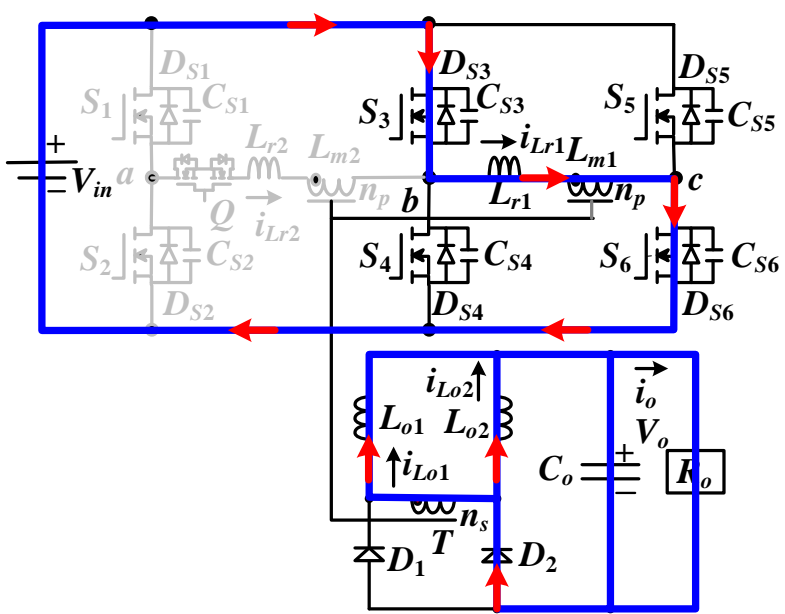

(a)

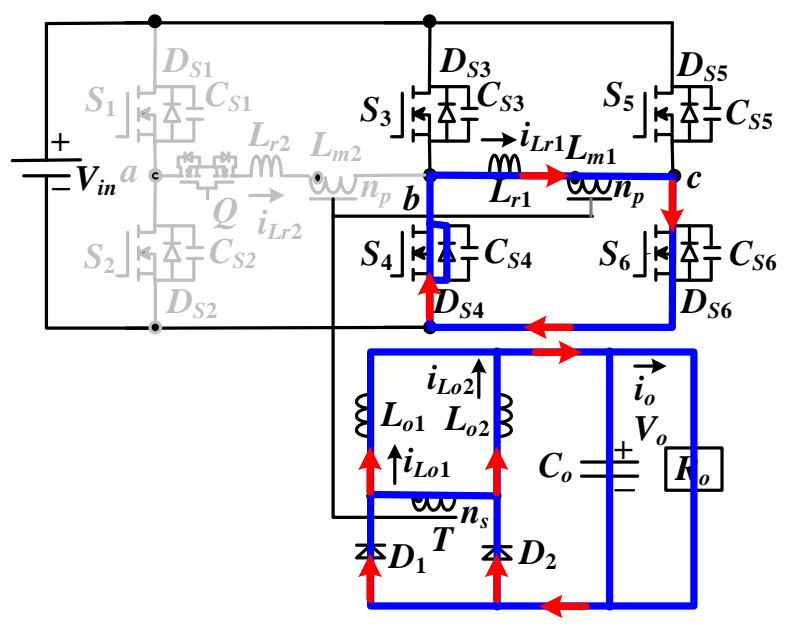

(c)

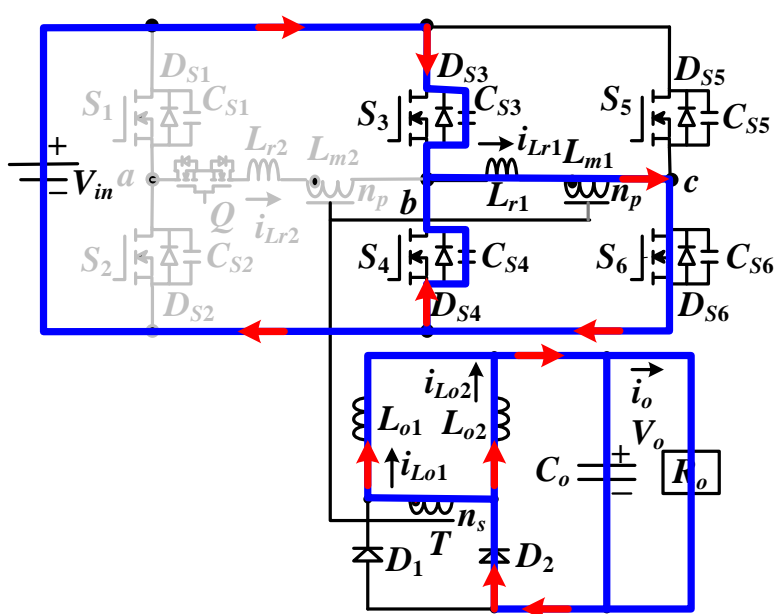

(b)

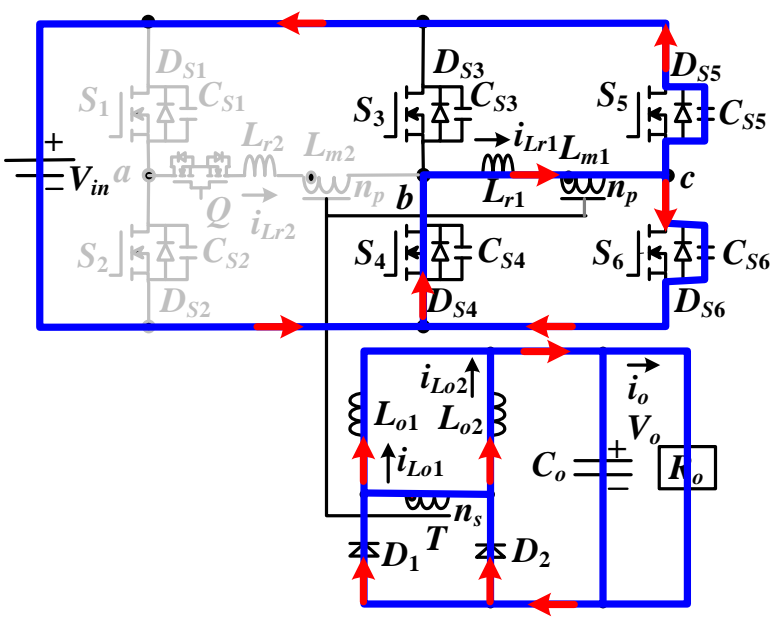

(d)

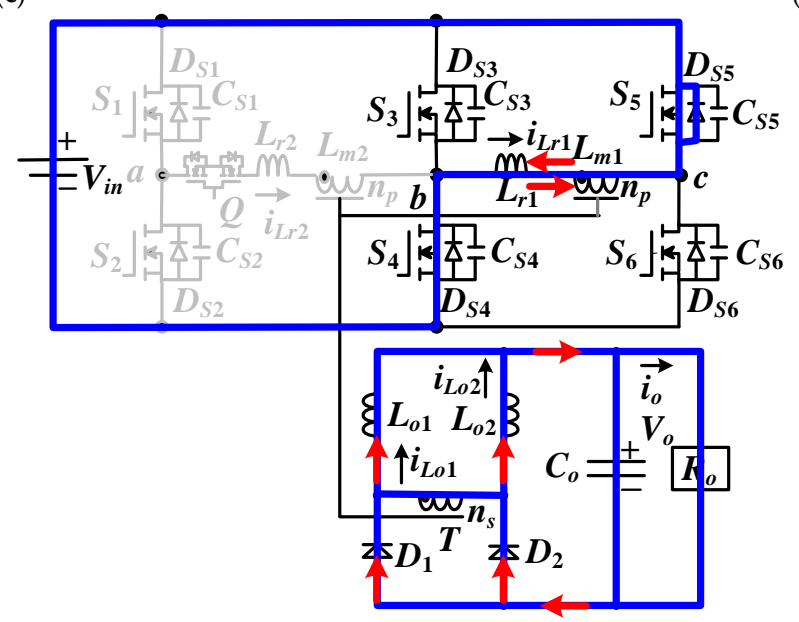

(e)

Figure 3. Equivalent circuits under low voltage input condition during the first half switching period: (a) step 1 circuit; (b) step 2 circuit; (c) step 3 circuit; (d) step 4 circuit; (e) step 5 circuit. 
Step $1\left[t_{0}, t_{1}\right]:$ At $t_{0}, i_{D 1}=0 . S_{3}$ and $S_{6}$ are active in this step. The leg voltage is $v_{b c}=$ $V_{\text {in }}, v_{L o 1}=V_{\text {in }} / N_{L}-V_{o}$, and $v_{L o 2}=-V_{o}$. Therefore, $i_{L o 1}$ will increase and $i_{L o 2}$ will decrease in this step. The primary and secondary inductor currents are given in Equations (1)-(3).

$$
\begin{gathered}
i_{L r 1}(t) \approx i_{L r 1}\left(t_{0}\right)+\frac{V_{i n}-N_{L} V_{o}}{N_{L}^{2} L_{o 1}}\left(t-t_{0}\right) \\
i_{L o 1}(t) \approx i_{L o 1}\left(t_{0}\right)+\frac{V_{i n} / N_{L}-V_{o}}{L_{o 1}}\left(t-t_{0}\right) \\
i_{L o 2}(t) \approx i_{L o 2}\left(t_{0}\right)-\frac{V_{o}}{L_{o 2}}\left(t-t_{0}\right)
\end{gathered}
$$

Step $2\left[t_{1}, t_{2}\right]: S_{3}$ turns OFF at time $t_{1} . i_{L r 1}\left(t_{1}\right)$ is positive and $C_{S 4}$ is discharged. $C_{S 4}$ can be discharged to zero at $t_{2}$ if Equation (4) is satisfied. Therefore, the ZVS operation of $S_{4}$ is achieved.

$$
\left(L_{r}+N_{L}^{2} L_{o}\right) i_{L r 1}^{2}\left(t_{1}\right) \geq 2 C_{o s s} V_{i n}^{2}
$$

The time $\Delta t_{12}$ in this step is expressed in Equation (5).

$$
\Delta t_{12} \approx 2 V_{\text {in }} C_{\text {oss }} N_{L} / i_{\text {Lo1 }}\left(t_{1}\right)
$$

where $i_{L o 1}\left(t_{1}\right) \approx i_{L o 1}\left(t_{0}\right)+\left(V_{\text {in }} / N_{L}-V_{o}\right) d_{e f f} T_{s w} / L_{o 1}$.

Step $3\left[t_{2}, t_{3}\right]$ : At $t_{2}, v_{C S 4}=0$ and $D_{S 4}$ is conducting due to $i_{L r 1}>0$. Thus, the ZVS turn-on operation of $S_{4}$ can be naturally realized. Due to leg voltage $v_{b c}=0, D_{1}$ and $D_{2}$ are both conducting. It can be observed that $v_{L o 1}=v_{L o 2}=-V_{o}$ and $v_{L r 1}=-v_{S 4, d p}-v_{S 6, d p}$, where $v_{S 4, d p}$ and $v_{S 6, d p}$ are voltage drops on $S_{4}$ and $S_{6}$. In step $3, i_{L o 1}, i_{L o 2}$ and $i_{L r 1}$ all decrease, $i_{D 1}$ increases and $i_{D 2}$ decreases.

Step $4\left[t_{3}, t_{4}\right]$ : At $t_{3}, S_{6}$ is turned off. $i_{L r 1}$ will charge $C_{S 6}$ and discharge $C_{S 5}$. The ZVS turn-on condition of $S_{5}$ is given in Equation (6).

$$
L_{r} i_{L r 1}^{2}\left(t_{3}\right) \geq 2 C_{\text {oss }} V_{\text {in }}^{2}
$$

Step 4 ends at $t_{4}$ when $v_{C S 5}=0$. The time $\Delta t_{34}$ in this step can be obtained in Equation (7).

$$
\Delta t_{34} \approx 2 V_{i n} C_{o s s} / i_{L r 1}\left(t_{3}\right)
$$

Step $5\left[t_{4}, t_{5}\right]$ : At $t_{4}, v_{C S 5}=0$. Then $D_{S 5}$ is conducting due to $i_{L r 1}\left(t_{4}\right)>0$. The ZVS operation of $S_{5}$ is naturally realized. In step 5 , the leg voltage $v_{b c}=-V_{\text {in }}$ and $D_{1}$ and $D_{2}$ are still conducting. The inductor voltage $v_{L r 1}=-V_{i n}$. The output filter inductor voltages $v_{L o 1}$ $=v_{L o 2}=-V_{o}$. Therefore, inductor currents $i_{L o 1}, i_{L o 2}$, and $i_{L r 1}$ all decrease. Step 5 ends at $t_{5}$ when $i_{D 2}=0$. The time duration $\Delta t_{45}$ is derived as Equation (8):

$$
\Delta t_{45} \approx\left(I_{0} L_{r}\right) /\left(V_{\text {in }} N_{L}\right)
$$

The duty loss in this step can be derived in Equation (9).

$$
d_{5} \approx\left(I_{o} L_{r} f_{s w}\right) /\left(V_{i n} N_{L}\right)
$$

where $f_{s w}$ is the switching frequency. Then, the circuit operation will go to next half switching cycle at time $t_{5}$.

For high voltage input operation $\left(2.3 V_{i n, \min } \leq V_{i n, H}<5 V_{i n, m i n}\right)$, ac switch $Q$ is ON and active devices $S_{4}$ and $S_{3}$ are OFF. Then, the full-bridge converter with switches $S_{1}, S_{2}$, $S_{5}$, and $S_{6}$, as shown in Figure 1c, is operated with duty cycle control. The transformer turns ratio on this equivalent circuit becomes $N_{H}=2 n_{p} / n_{s}$. The dc gain can be expressed as $V_{o} / V_{i n, H} \approx d_{\text {eff }} / N_{H}$. This can be observed in Figure 2b. The converter has five steps in one-half of the switching period. The corresponding step circuits are given in Figure 4, and the circuit operations are explained briefly in the following discussions. 


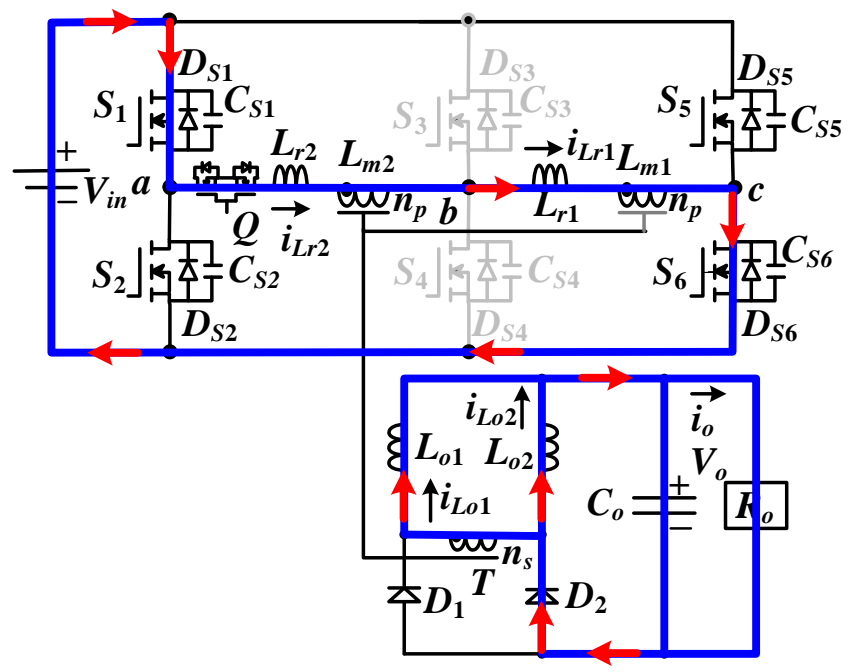

(a)

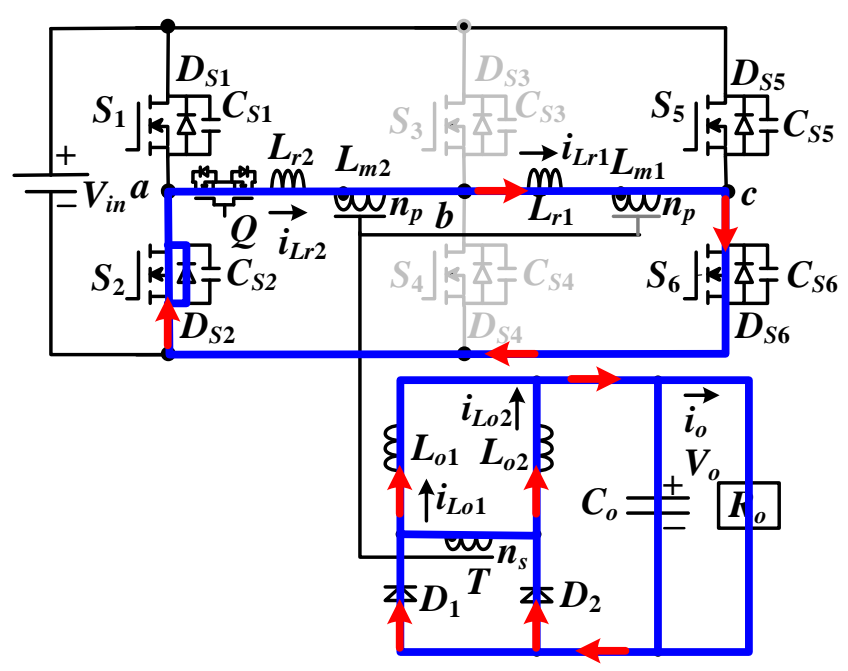

(c)

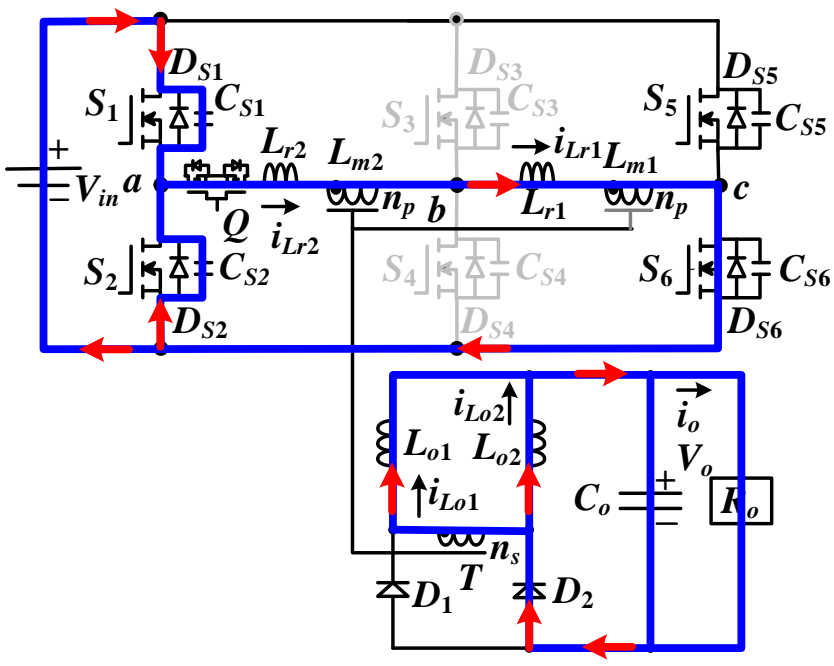

(b)

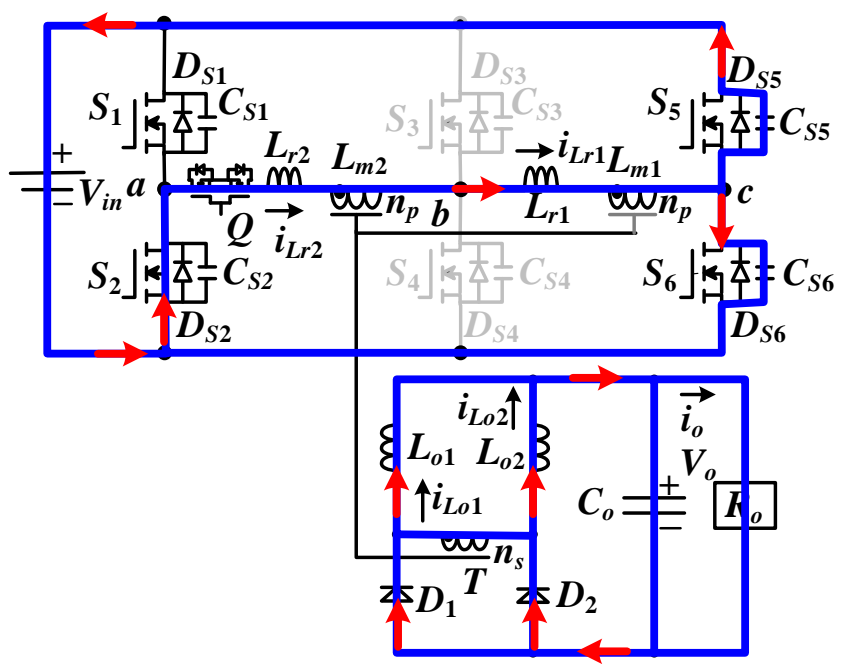

(d)

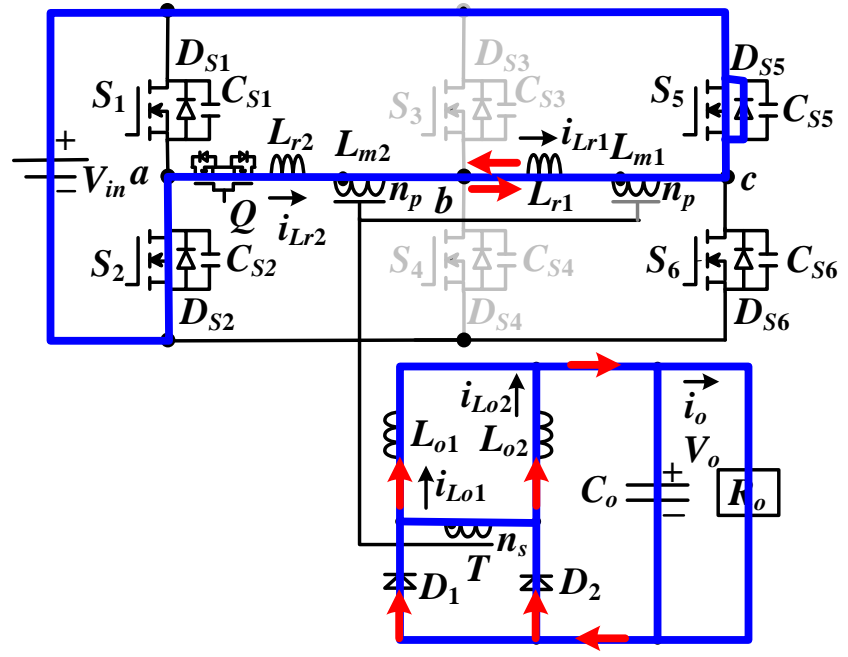

(e)

Figure 4. Equivalent circuits under high voltage input condition during the first half switching period: (a) step 1 circuit; (b) step 2 circuit; (c) step 3 circuit; (d) step 4 circuit;(e) step 5 circuit. 
Step $1\left[t_{0}, t_{1}\right]$ : The current $i_{D 1}=0$ at $t_{0}$. Thus, $D_{1}$ is OFF. In step $1, S_{1}$ and $S_{6}$ are conducting, $v_{a c}=V_{i n}, v_{L o 1}=V_{i n} / N_{H}-V_{o}$, and $v_{L o 2}=-V_{o}$. The currents $i_{L r 1}$ and $i_{L o 1}$ increase and $i_{\text {Lo2 }}$ decreases. Step 1 ends at $t_{1}$ when $S_{1}$ turns off.

Step $2\left[t_{1}, t_{2}\right]: S_{1}$ is turned off at $t_{1} . i_{L r 1}=i_{L r 2}>0$ and $C_{S 2}\left(C_{S 1}\right)$ is discharged (charged) by $i_{\text {Lr2 }}$. The ZVS turn-on operation of $S_{2}$ is expressed as Equation (10):

$$
\left(2 L_{r}+N_{H}^{2} L_{o}\right) i_{L r 2}^{2}\left(t_{1}\right) \geq 2 C_{o s s} V_{i n}^{2}
$$

Step $3\left[t_{2}, t_{3}\right]: v_{C S 2}\left(t_{2}\right)=0 . i_{L r 2}>0$ and $D_{S 2}$ is forward biased. At this moment, $S_{2}$ is turned ON under zero voltage. The leg voltage $v_{a c}=0$ and both diodes $D_{1}$ and $D_{2}$ conducting. Therefore, $v_{L o 1}=v_{L o 2}=-V_{O}$ and $v_{L r 1}+v_{L r 2}=-v_{S 2, d r o p}-v_{S 6, \text { drop }}-v_{Q, \text { drop }}$. The currents $i_{L o 1}, i_{L o 2}, i_{L r 1}$, and $i_{D 2}$ decrease and $i_{D 1}$ increases.

Step $4\left[t_{3}, t_{4}\right]: S_{6}$ turns OFF at $t_{3} . i_{L r 1}$ charges (discharges) $C_{S 6}\left(C_{S 5}\right)$. The ZVS turn-on condition of $S_{5}$ is obtained as Equation (11):

$$
2 L_{r} i_{L r 2}^{2}\left(t_{3}\right) \geq 2 C_{o s s} V_{i n}^{2}
$$

This step ends at $t_{4}$ when $C_{S 5}$ is discharged to zero voltage.

Step $5\left[t_{4}, t_{5}\right]: v_{C S 5}\left(t_{4}\right)=0$. Since $i_{L r 1}\left(t_{4}\right)$ is positive, $D_{S 5}$ becomes forward biased. In this step, $v_{a c}=-V_{i n}$ and $D_{2}$ and $D_{1}$ are ON. It can be obtained that $v_{L r 1}+v_{L r 2}=-V_{i n}$, and $v_{L o 2}=v_{L o 1}=-V_{o} . i_{L o 2}, i_{L o 1}$, and $i_{L r 1}$ all decrease. This step ends at $t_{5}$ when $i_{D 2}=0$. The time $\Delta t_{45}$ is obtained as Equation (12):

$$
\Delta t_{45} \approx\left(2 I_{o} L_{r}\right) /\left(V_{i n} N_{H}\right)
$$

The duty loss can be calculated in Equation (13).

$$
d_{5} \approx\left(2 I_{o} L_{r} f_{s w}\right) /\left(V_{i n} N_{H}\right)
$$

At $t_{5}$, the circuit operation will go to the next half switching period.

\section{Steady State Analysis}

In relation to the ON/OFF status of $Q$ and $S_{1}-S_{6}$, two equivalent sub-circuits shown in Figure 1 are operated to have a wide voltage input operation and a ZVS turn-on operation. According to the voltage-second balance on $L_{01}$ or $L_{02}$, the load voltage $V_{o}$ can be expressed as Equation (14):

$$
V_{o}=\left\{\begin{array}{l}
\frac{n_{s} V_{i n, L}}{n_{p}}\left(d-\frac{n_{s} I_{o} L_{r} f_{s w}}{n_{p} V_{i n, L}}\right)-V_{D}, V_{i n, \min } \leq V_{i n, L}<2.3 V_{i n, \text { min }} \\
\frac{n_{s} V_{i n, H}}{2 n_{p}}\left(d-\frac{n_{s} I_{o} L_{r} f_{s w}}{n_{p} V_{i n, H}}\right)-V_{D}, 2.3 V_{i n, \min }<V_{i n, L} \leq 5 V_{i n, \text { min }}
\end{array}\right.
$$

where $d$ is the duty cycle on voltage $v_{a c}$ or $v_{b c}$. For the low voltage input condition, $N_{L}=n_{p} / n_{s}$ is obtained as Equation (15):

$$
N_{L}=\frac{V_{i n, L}}{\left(V_{o}+V_{D}\right)}\left(d-\frac{I_{0} L_{r} f_{s w}}{N_{L} V_{i n, L}}\right)
$$

The winding turns of transformer $T$ are expressed as $n_{p} \geq\left(V_{i n, \min } d_{\max } T_{s w}\right) /\left(\Delta B A_{e}\right)$ and $n_{s}=n_{p} / N_{L}$. If the duty loss in (9) is defined, $L_{r 1}$ and $L_{r 2}$ can be approximated as Equation (16):

$$
L_{r}=L_{r 1}=L_{r 2}=\frac{N_{L} d_{5} V_{i n}}{f_{s w} I_{o}}
$$


In the presented circuit, the load current is equally distributed on inductors $L_{01}$ and $L_{O 2}$, and $I_{L o 1}=I_{L o 2}=I_{0} / 2$. If the ripple currents of $L_{01}$ and $L_{O 2}$ are identical (i.e., $\Delta i_{L o 1}=$ $\left.\Delta i_{L o 1}=\Delta i_{L o}\right)$, then $L_{o 1}=L_{o 2}=L_{o}$ can be calculated in Equation (17).

$$
L_{o}=\frac{\left(V_{o}+V_{D}\right)}{\Delta i_{L o} f_{s w}}\left(1-d+\frac{n_{s} I_{o} L_{r} f_{s w}}{n_{p} V_{i n, L}}\right)
$$

Then, the winding turns of $L_{o 1}$ and $L_{o 2}$ are obtained as $n_{L o} \geq\left[L_{o}\left(I_{o}+\Delta i_{L o}\right) / 2\right] /$ $\left(B_{\max } A_{e}\right)$. The peak switch currents are approximated as Equation (18):

$$
i_{S x, p a e k} \approx \frac{\left(I_{o}+\Delta i_{L o}\right) / 2}{N_{L}}+\frac{\Delta i_{L m}}{2}=\frac{\left(I_{o}+\Delta i_{L o}\right) / 2}{N_{L}}+\frac{d V_{i n, L} T_{s w}}{2 L_{m}}-\frac{L_{r} I_{o}}{2 N_{L} L_{m}}
$$

where $x=1 \sim 6$. From the ZVS conditions in (4) and (6), the ZVS operation of leading-leg switches are easier to achieve than lagging-leg switches under the given inductance $L_{r 1}$. The necessary inductances $L_{r 1}=L_{r 2}=L_{r 2}$ are derived as $L_{r} \geq 2 C_{o s s} V_{i n}^{2} / i_{L r 1}^{2}\left(t_{3}\right)$ to achieve the ZVS operation of lagging-leg switches $S_{5}$ and $S_{6}$. The voltage stress of $S_{1}-S_{6}$ and $Q$ is $V_{\text {in,max }}$. The voltage stress and dc currents of $D_{2}$ and $D_{1}$ are obtained as $V_{\text {in,max }} / N_{L}$ and $I_{0} / 2$, respectively.

\section{Experimental Results}

The performance of the converter is confirmed from a laboratory circuit with $800 \mathrm{~W}$ rated power. The electric specifications of the test circuit are $V_{\text {in }}=120-600 \mathrm{~V}$, the output voltage $V_{o}=48 \mathrm{~V}$, the maximum power $P_{o}=800 \mathrm{~W}$, and $f_{s w}=140 \mathrm{kHz}$. The presented converter operates in the low voltage input condition if $120 \mathrm{~V} \leq V_{\text {in }}<270 \mathrm{~V}$. Then, $Q, S_{1}$, and $S_{2}$ are OFF. Likewise, the presented converter operates in the high voltage condition if $270 \mathrm{~V}<V_{\text {in }} \leq 600 \mathrm{~V}$. For the high voltage input operation, $S_{3}$ and $S_{4}$ are OFF and $Q$ is ON. A Schmitt trigger circuit with $\pm 20 \mathrm{~V}$ voltage tolerance is selected to avoid control signal oscillation at the transition voltage $270 \mathrm{~V}$. Therefore, the actual low and high voltage input ranges are $V_{i n, L}=120-290 \mathrm{~V}$ and $V_{i n, H}=250-600 \mathrm{~V}$. Figure 5a gives the circuit parameters of a prototype circuit. The phase-shift PWM integrated circuit UCC3895 is selected to produce the gating waveforms of $S_{5}$ and $S_{6}$. The gating waveforms of $S_{1}-S_{4}$ are generated by the logic gates and PWM output of UCC3895. Figure 5b gives the picture of the prototype circuit in the laboratory test.

The experimental waveforms of the proposed converter at a low voltage input range $\left(V_{\text {in }}=120 \sim 290 \mathrm{~V}\right)$ are given in Figures 6-9. The measured results under a high voltage input range $\left(V_{\text {in }}=250 \sim 600 \mathrm{~V}\right)$ are given in Figures 10-13. Figure 6 provides the experimental primary-side (Figure 6a) and secondary-side (Figure 6b) waveforms at $V_{\text {in }}=120 \mathrm{~V}$ and $P_{o}=$ $800 \mathrm{~W}$. Note that the duty cycle on voltage $v_{b c}$ is close to 0.5 , the ripple current on $i_{L o 1}+i_{L o 2}$ is reduced compared to the ripple current on $i_{L o 1}$ or $i_{L o 2}$, and the resultant current $i_{L o 1}+$ $i_{\text {Lo2 }}$ has twice the switching frequency of currents $i_{\text {Lo1 }}$ and $i_{L o 2}$. Figure 7a,b gives the PWM signal of $S_{3}$ at $20 \%$ power and $100 \%$ power with the $V_{i n}=120 \mathrm{~V}$ input case. In the same way, the PWM waveform of $S_{5}$ (lagging-leg switch) at 50\% and $100 \%$ loads are illustrated in Figure $7 \mathrm{c}, \mathrm{d}$. Figures 8 and 9 provide the measured results of the presented converter operated at $V_{\text {in }}=290 \mathrm{~V}$ in the low voltage input region. Since the higher input voltage will result in a lower duty cycle, it is clear that the voltage $v_{b c}$ at $V_{i n}=290 \mathrm{~V}$ input has less duty ratio than in the $V_{\text {in }}=120 \mathrm{~V}$ input condition. It can also be noted in Figures $6 \mathrm{~b}$ and $8 \mathrm{~b}$ that $i_{L o 1}+i_{L o 2}$ has more ripple current at $V_{i n}=290 \mathrm{~V}$ than $V_{i n}=120 \mathrm{~V}$. Figure 9 gives the experimental waveforms of $S_{3}$ in leading leg and $S_{5}$ in lagging leg in the $290 \mathrm{~V}$ input condition. It can be observed from Figures 7 and 9 that the ZVS turn-on operation of $S_{3}$ is realized from $20 \%$ power for both $120 \mathrm{~V}$ and $290 \mathrm{~V}$ input conditions. Likewise, the ZVS turn-on operation of $S_{5}$ is accomplished from $50 \%$ power under $120 \mathrm{~V}$ and $290 \mathrm{~V}$ input cases. For a high voltage input range ( $Q$ is $\mathrm{ON}$ and $S_{3}$ and $S_{4}$ are OFF), the test results are shown in Figures $10-13$. For $V_{\text {in }}=250 \mathrm{~V}$, the experimental results at $100 \%$ power are given in Figure 10. The PWM signals of $S_{1}$ and $S_{5}$ are given in Figure 11. In the same way, 
the experimental waveforms for $V_{i n}=600 \mathrm{~V}$ input are given in Figures 12 and 13 . From the experimental results in Figures 7, 9, 11 and 13, it can be observed that the leading-leg switch, such as $S_{1}$ and $S_{3}$, can achieve ZVS operation from $20 \%$ load, and the ZVS operation of $S_{5}$ in the lagging leg is from $50 \%$ power. The measured results of $V_{i n}, v_{Q, g}, v_{S 1, g}$, and $v_{S 3, g}$ between $120 \mathrm{~V}$ and $600 \mathrm{~V}$ input are shown in Figure 14. When $V_{\text {in }}$ is increased from $120 \mathrm{~V}$ to $290 \mathrm{~V}$, the presented circuit is controlled in the low voltage input range. $Q, S_{1}$, and $S_{2}$ are OFF and $S_{3}$ and $S_{4}$ are controlled with the phase-shift PWM approach. When $V_{\text {in }}$ $>290 \mathrm{~V}, Q$ is ON and $S_{3}$ and $S_{4}$ are OFF. $S_{1}$ and $S_{2}$ are operated with duty cycle control. When $V_{\text {in }}$ is decreased from $600 \mathrm{~V}$ to $250 \mathrm{~V}$, the converter is controlled in the high voltage input range. The switch $Q$ is $\mathrm{ON}$ and $S_{3}$ and $S_{4}$ are OFF. The test results in Figure 14 are in agreement with the theoretical analysis. The test efficiencies of the proposed converter are $89.3 \%$ and $91.2 \%$ for $120 \mathrm{~V}$ and $600 \mathrm{~V}$ input cases under a full load. The synchronous rectifiers can be further used on the secondary side to reduce the conduction losses on $D_{1}$ and $D_{2}$ and improve the converter efficiency.

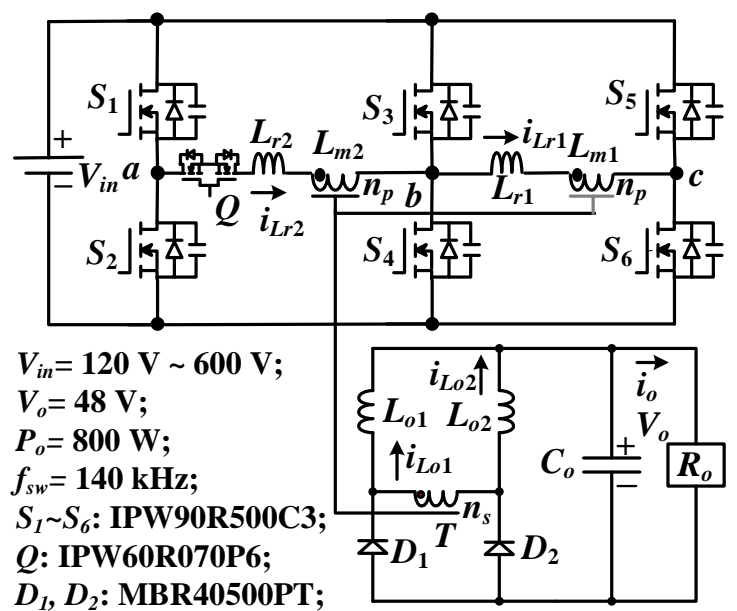

$L_{r 1}, L_{r 2}: 15 \mu \mathrm{H}$;

$L_{m 1}, L_{m 2}: 0.5 \mathrm{mH}$;

$L_{o 1}, L_{o 2}: 80 \mu \mathrm{H}$;

$C_{o}: 63 \mathrm{~V} / 1100 \mu \mathrm{F}$;

$n_{p}: n_{p}: n_{s}=11: 11: 14$

(a)

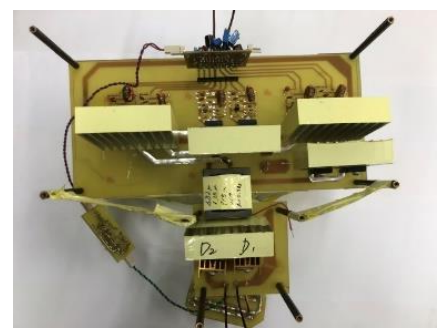

(b)

Figure 5. Laboratory prototype: (a) circuit diagram; (b) picture of prototype circuit.

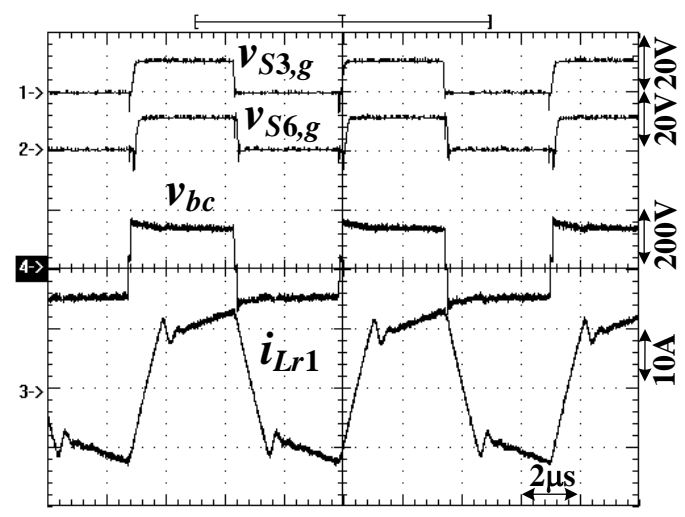

(a)

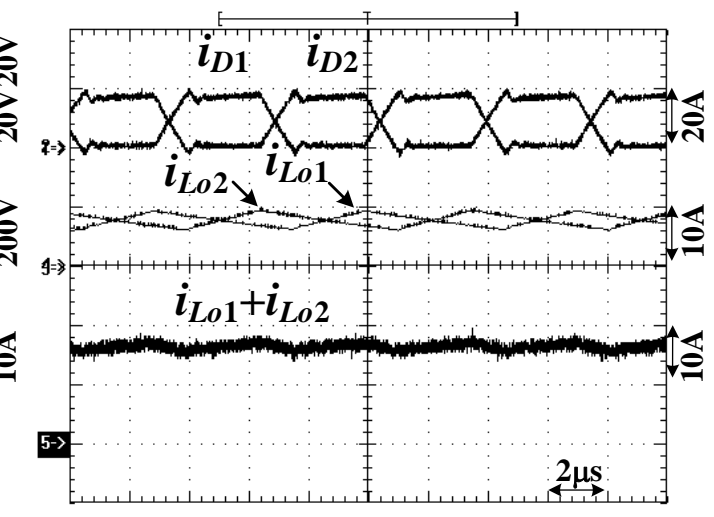

(b)

Figure 6. Test waveforms at $V_{\text {in }}=120 \mathrm{~V}$ (low voltage input range) and $P_{o}=800 \mathrm{~W}$ : (a) primary-side waveforms $v_{S 3, g}, v_{S 5, g}$, $v_{b c}$, and $i_{L r 1} ;(\mathbf{b})$ secondary-side waveforms $i_{D 1}, i_{D 2}, i_{L o 1}, i_{L o 2}$, and $i_{L o 1}+i_{L o 2}$. 


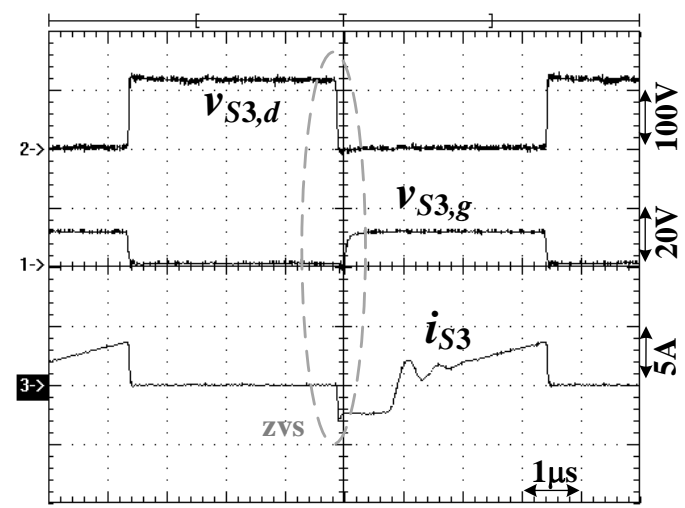

(a)

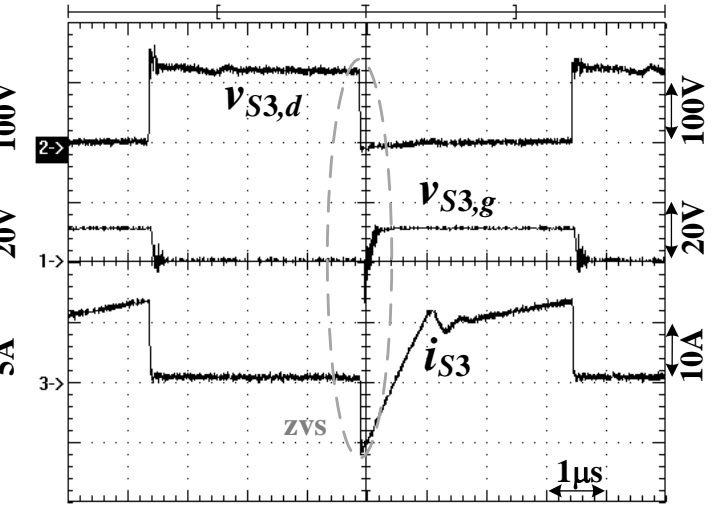

(b)

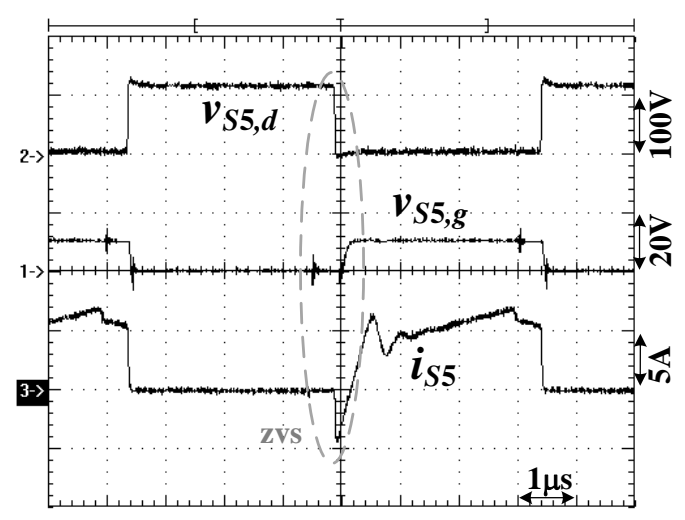

(c)

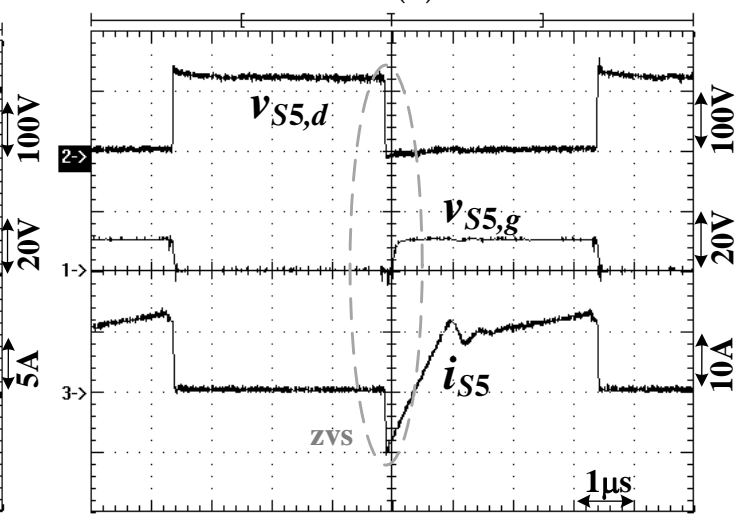

(d)

Figure 7. Test waveforms of $S_{3}$ and $S_{5}$ at $V_{\text {in }}=120 \mathrm{~V}$ (low voltage input range): (a) $S_{3}$ under $20 \%$ load; (b) $S_{3}$ under $100 \%$ load; (c) $S_{5}$ under $20 \%$ load; (d) $S_{5}$ under $100 \%$ load.

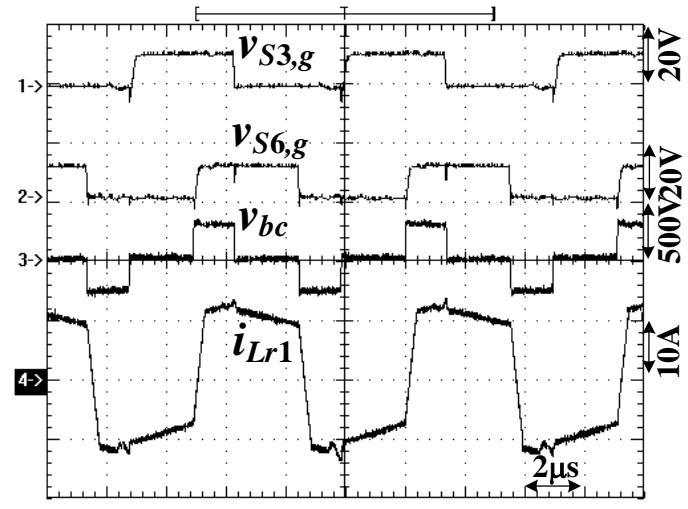

(a)

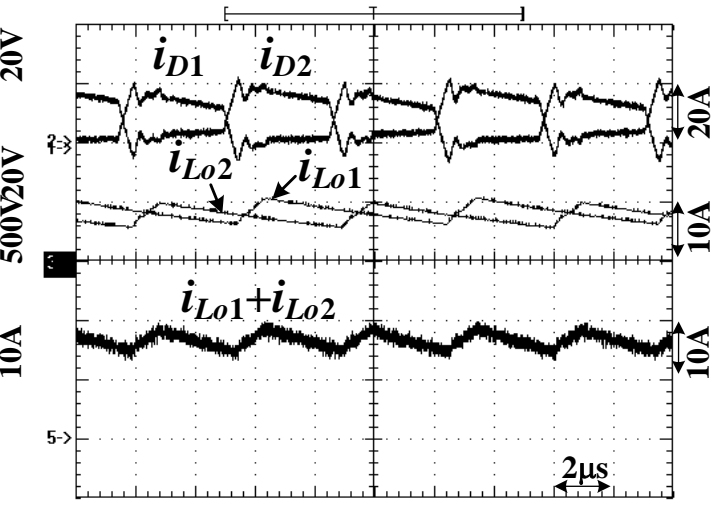

(b)

Figure 8. Test waveforms at $V_{\text {in }}=290 \mathrm{~V}$ (low voltage input range) and $P_{o}=800 \mathrm{~W}$ : (a) primary-side waveforms $v_{S 3, g}, v_{S 5, g}$, $v_{b c}$, and $i_{L r 1} ;(\mathbf{b})$ secondary-side waveforms $i_{D 1}, i_{D 2}, i_{L o 1}, i_{L o 2}$, and $i_{L o 1}+i_{L o 2}$. 


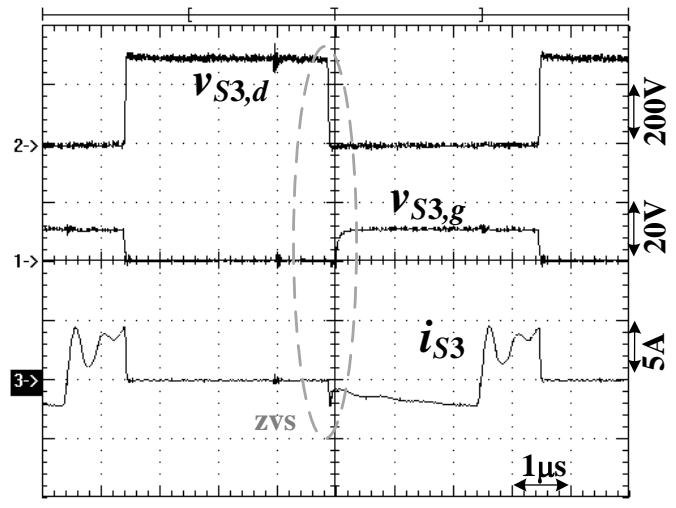

(a)

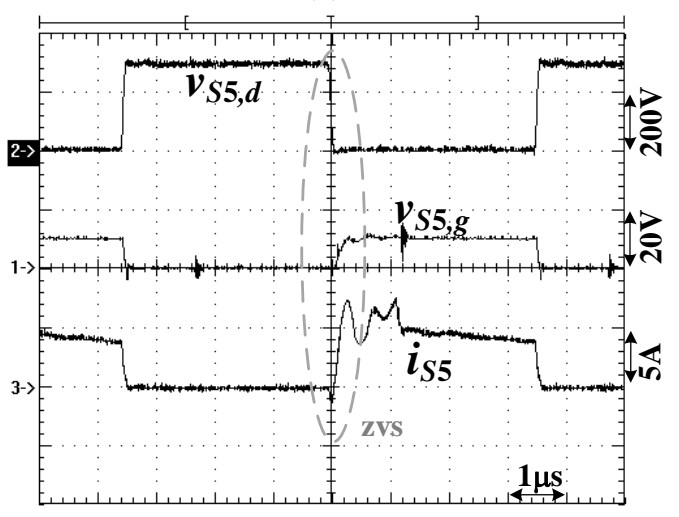

(c)

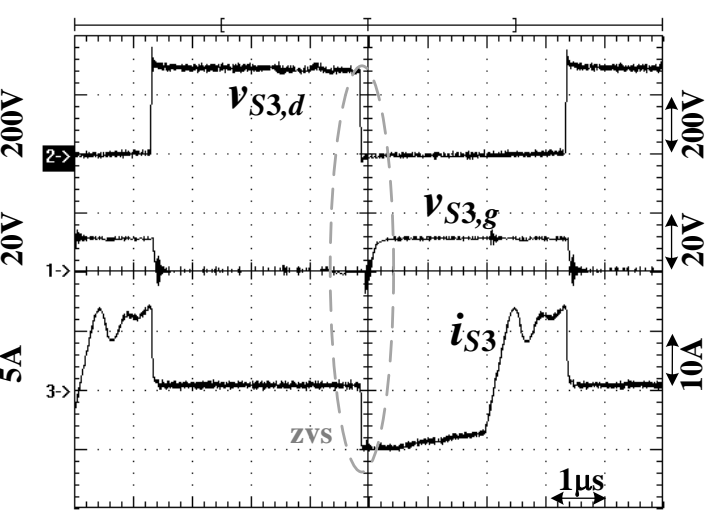

(b)

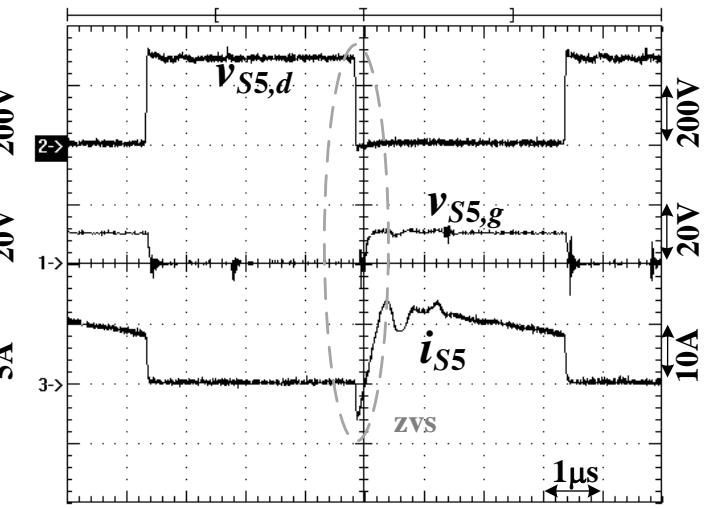

(d)

Figure 9. Test waveforms of $S_{3}$ and $S_{5}$ at $V_{\text {in }}=290 \mathrm{~V}$ (low voltage input range): (a) $S_{3}$ under $20 \%$ load; (b) $S_{3}$ under $100 \%$ load; (c) $S_{5}$ under $20 \%$ load; (d) $S_{5}$ under $100 \%$ load.

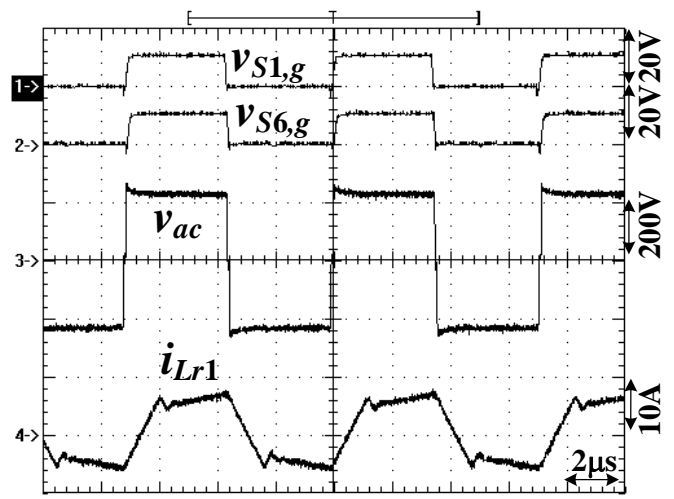

(a)

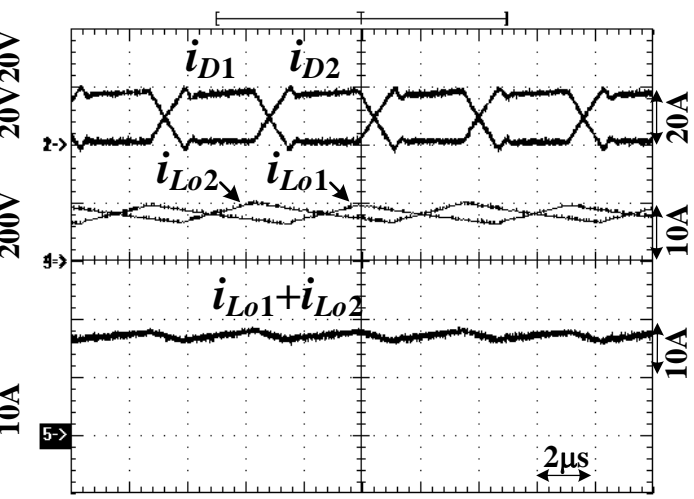

(b)

Figure 10. Test waveforms at $V_{i n}=250 \mathrm{~V}$ and $P_{o}=800 \mathrm{~W}$ : (a) primary-side waveforms $v_{S 1, g}, v_{S 5, g}, v_{a c}$, and $i_{L r 1}$; (b) secondaryside waveforms $i_{D 1}, i_{D 2}, i_{L o 1}, i_{L o 2}$, and $i_{L o 1}+i_{L o 2}$. 


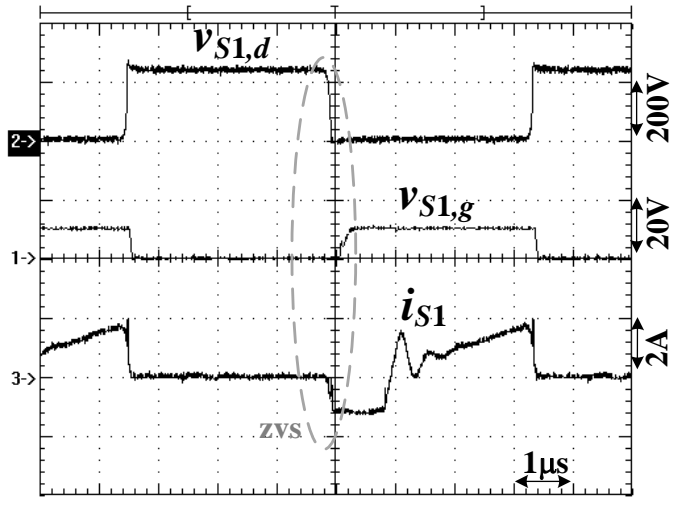

(a)

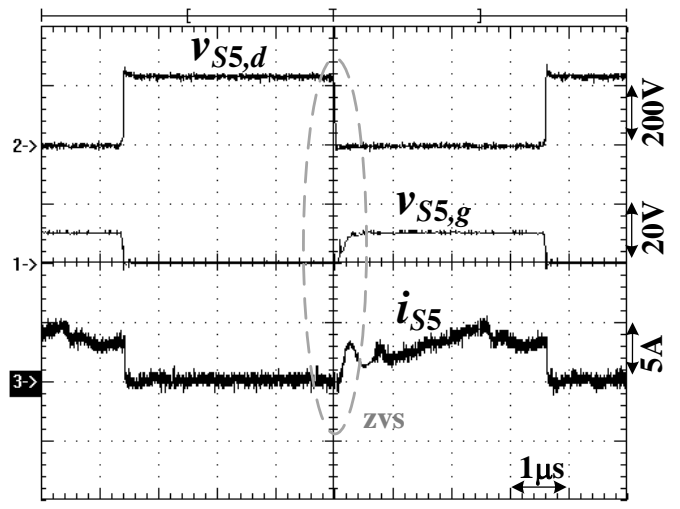

(c)

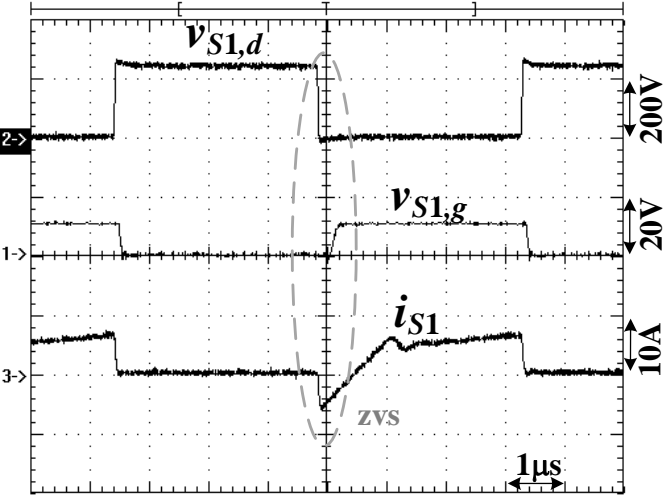

(b)

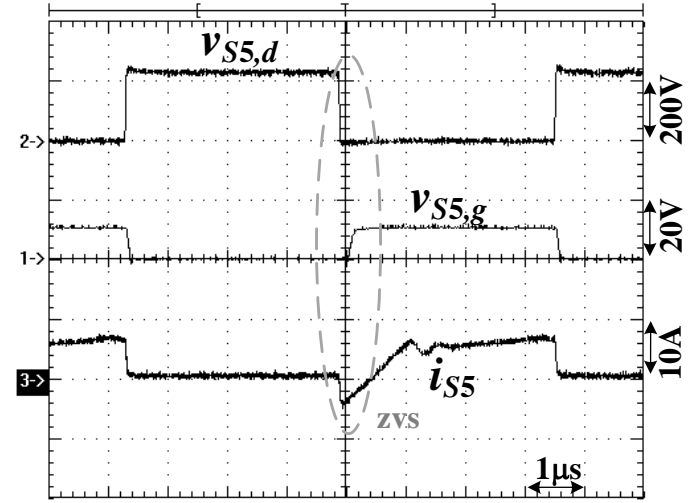

(d)

Figure 11. Test waveforms of $S_{1}$ and $S_{5}$ at $V_{\text {in }}=250 \mathrm{~V}$ : (a) $S_{1}$ under $20 \%$ load; (b) $S_{1}$ under $100 \%$ load; (c) $S_{5}$ under $20 \%$ load; (d) $S_{5}$ under $100 \%$ load.

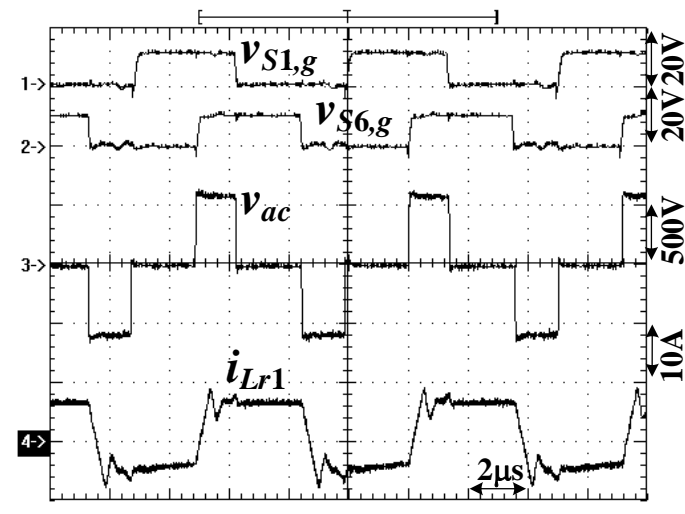

(a)

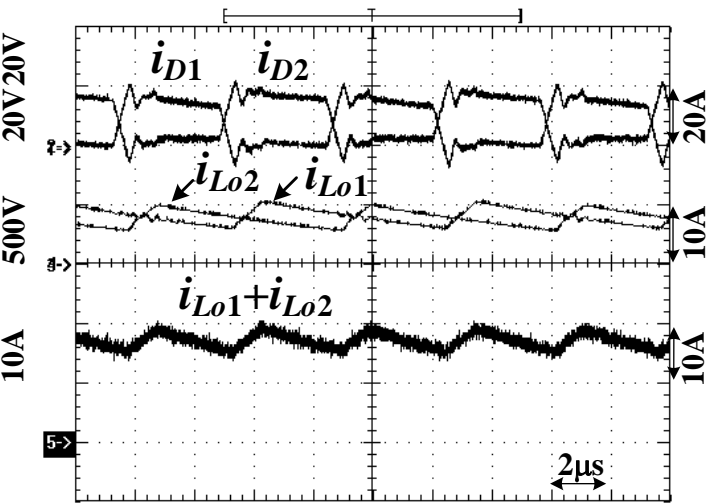

(b)

Figure 12. Test waveforms at $V_{i n}=600 \mathrm{~V}$ and $P_{o}=800 \mathrm{~W}$ : (a) primary-side waveforms $v_{S 1, g}, v_{S 5, g}, v_{a c}$, and $i_{L r 1}$; (b) secondaryside waveforms $i_{D 1}, i_{D 2}, i_{L o 1}, i_{L o 2}$, and $i_{L o 1}+i_{L o 2}$. 


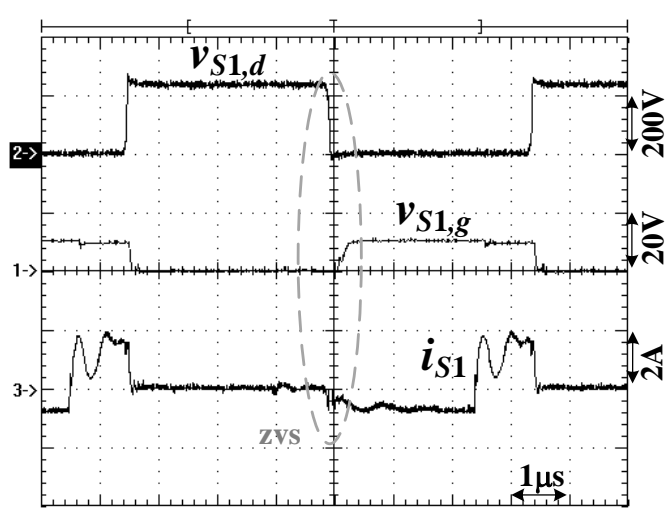

(a)

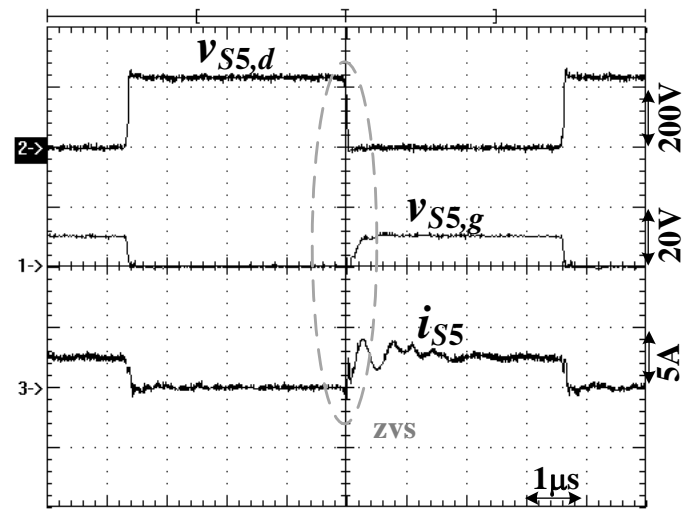

(c)

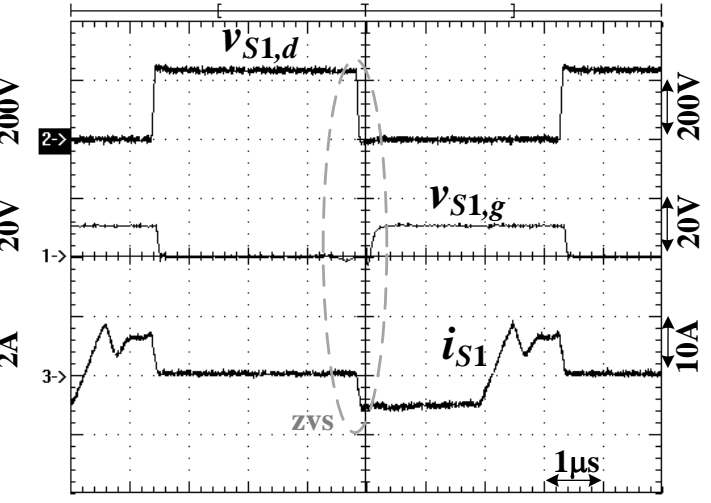

(b)

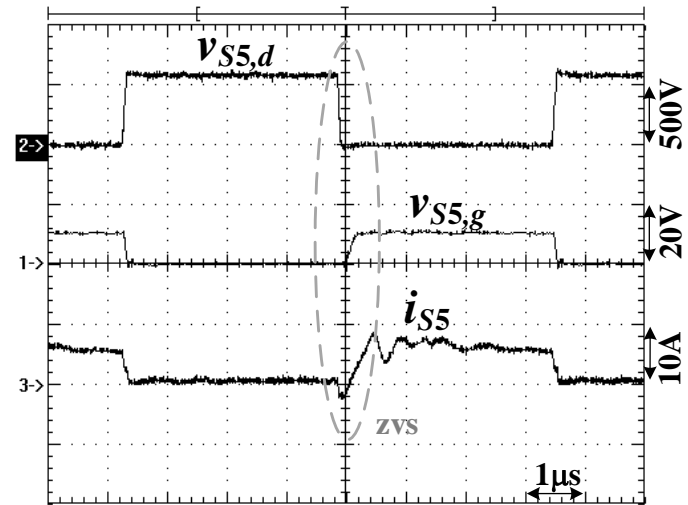

(d)

Figure 13. Test waveforms of $S_{1}$ and $S_{5}$ at $V_{\text {in }}=600 \mathrm{~V}$ : (a) $S_{1}$ under $20 \%$ load; (b) $S_{1}$ under $100 \%$ load; (c) $S_{5}$ under $20 \%$ load; (d) $S_{5}$ under $100 \%$ load.

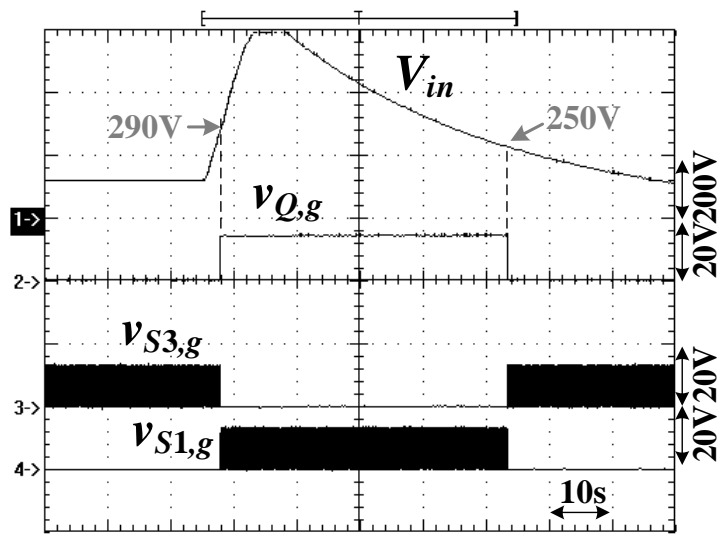

Figure 14. Test waveforms of $V_{i n}, v_{Q, g}, v_{S 1, g}$, and $v_{S 3, d}$ under $V_{\text {in }}=120-600 \mathrm{~V}$ variation.

\section{Conclusions}

A ZVS converter with three-leg circuit topology is presented and discussed, and an $800 \mathrm{~W}$ prototype is constructed and measured to achieve ZVS operation and a wide voltage input operation. The presented converter is expected to be used for dc converters with wide input-voltage or output-voltage demand such as dc wind power applications, battery charger systems with wide voltage operation, and solar PV panel power units with variable input voltage. The proposed converter with a phase-shift PWM scheme can be operated at two equivalent circuits. Therefore, active devices in the leading leg are easily turned on under zero voltage. The current doubler rectification circuit is operated on the low-voltage side in order to have less output ripple current. Compared to conventional phase-shift PWM converters, the studied circuit topology has a wider voltage input capability with 
the drawback of using an extra three switches in the presented converter. Finally, test results with an $800 \mathrm{~W}$ prototype are provided to demonstrate circuit characteristics and the validity of the operating principle.

Author Contributions: Conceptualization, methodology, investigation, visualization, writingoriginal draft, writing-review and editing, B.-R.L.; validation, Y.-H.P. All authors have read and agreed to the published version of the manuscript.

Funding: This research is supported by the Ministry of Science and Technology (MOST), Taiwan, under grant number MOST 108-2221-E-224-022-MY2.

Acknowledgments: The authors are grateful to all of the editors and reviewers for their valuable suggestions to improve this paper.

Conflicts of Interest: The authors declare no conflict of interest.

\section{References}

1. Jumani, T.A.; Mustafa, M.W.; Rasid, M.M.; Anjum, W.; Ayub, S. Salp Swarm Optimization Algorithm-Based Controller for Dynamic Response and Power Quality Enhancement of an Islanded Microgrid. Processes 2019, 7, 840. [CrossRef]

2. Nasir, M.; Iqbal, S.; Khan, H.A.; Guerrero, J.M. Sustainable Rural Electrification Through Solar PV DC Microgrids-An Architecture-Based Assessment. Processes 2020, 8, 1417. [CrossRef]

3. Luo, Z.; Zhu, Z.; Zhang, Z.; Qin, J.; Wang, H.; Gao, Z.; Yang, Z. Multi-Time-Scale Rolling Optimal Dispatch for Grid-Connected AC/DC Hybrid Microgrids. Processes 2019, 7, 961. [CrossRef]

4. Sheng, W.; Hong, Y.; Wu, M.; Ji, Y. A Cooperative Control Scheme for AC/DC Hybrid Autonomous Microgrids. Processes 2020, 8, 311. [CrossRef]

5. Jiang, Y.; Jin, X.; Wang, H.; Fu, Y.; Ge, W.; Yang, B.; Yu, T. Optimal Nonlinear Adaptive Control for Voltage Source Converters via Memetic Salp Swarm Algorithm: Design and Hardware Implementation. Processes 2019, 7, 490. [CrossRef]

6. Ali, H.G.; Arbos, R.V.; Herrera, J.; Peláez-Restrepo, J. Non-Linear Sliding Mode Controller for Photovoltaic Panels with Maximum Power Point Tracking. Processes 2020, 8, 108.

7. Lin, B.R. Hybrid dc/dc Converter Based on Dual Three-Level Circuit and Half-Bridge Circuit. IET Power Electron. 2016, 9, 817-824. [CrossRef]

8. Safaee, A.; Jain, P.; Bakhshai, A. A ZVS Pulsewidth Modulation Full-Bridge Converter with a Low rms Current Resonant Auxiliary Circuit. IEEE Trans. Power Electron. 2016, 31, 4031-4047. [CrossRef]

9. Ren, R.; Liu, B.; Jones, E.A.; Wang, F.F.; Zhang, Z.; Costinett, D. Capacitor-Clamped, Three-Level Gan-Based dc-dc Converter with Dual Voltage Outputs for Battery Charger Applications. IEEE J. Emerg. Sel. Top. Power Electron. 2016, 4, 841-853. [CrossRef]

10. Steigerwald, R.L. A Comparison of Half-Bridge Resonant Converter Topologies. IEEE Trans. Power Electron. 1988, 3, 174-182. [CrossRef]

11. Lin, B.R.; Chu, C.W. Hybrid Full-Bridge and LLC Converter with Wide ZVS Range and Less Output Inductance. IET Power Electron. 2016, 9, 377-384. [CrossRef]

12. Lee, J.B.; Kim, J.K.; Baek, J.I.; Kim, J.H.; Moon, G.W. Resonant Capacitor on/off Control of Half-Bridge LLC Converter for High Efficiency Server Power Supply. IEEE Trans. Ind. Electron. 2016, 63, 5410-5415. [CrossRef]

13. Jeong, Y.; Kim, J.K.; Lee, J.B.; Moon, G.W. An Asymmetric Half-Bridge Resonant Converter Having a Reduced Conduction Loss for DC/DC Power Applications with a Wide Range of Low Input Voltage. IEEE Trans. Power Electron. 2017, 32, 7795-7804. [CrossRef]

14. Zhang, Y.; Fu, C.; Sumner, M.; Wang, P. A Wide Input-Voltage Range Quasi-Z-Source Boost DC-DC Converter with High-Voltage Gain for Fuel Cell Vehicles. IEEE Trans. Ind. Electron. 2018, 65, 5201-5212. [CrossRef]

15. Wang, P.; Zhou, L.; Zhang, Y.; Li, J.; Sumner, M. Input-Parallel Output-Series DC-DC Boost Converter with a Wide Input Voltage Range, for Fuel Cell Vehicles. IEEE Trans. Veh. Tech. 2017, 66, 7771-7781. [CrossRef]

16. Wang, X.; Tian, F; Batarseh, I. High Efficiency Parallel Post Regulator for Wide Range Input DC-DC Converter. IEEE Trans. Power Electron. 2008, 23, 852-858. [CrossRef]

17. Lu, J.; Kumar, A.; Afridi, K.K. Step-Down Impedance Control Network Resonant DC-DC Converter Utilizing an Enhanced Phase-Shift Control for Wide-Input-Range Operation. IEEE Trans. Ind. Appl. 2018, 54, 4523-4536. [CrossRef]

18. Li, W.; Zong, S.; Liu, F.; Yang, H.; He, X.; Wu, B. Secondary-Side Phase-Shift-Controlled ZVS DC/DC Converter with Wide Voltage Gain for High Input Voltage Applications. IEEE Trans. Power Electron. 2013, 28, 5128-5139. [CrossRef]

19. Kim, B.; Kim, S.; Hun, D.Y.; Choi, J.H.; Kim, M. Hybrid Resonant Half-Bridge DC/DC Converter with Wide Input Voltage Range. In Proceedings of the IEEE APEC Conference, San Antonio, TX, USA, 4-8 March 2018; pp. 1876-1881. 
20. Hu, H.; Fang, X.; Chen, F.; Shen, Z.J.; Batarseh, I. A Modified High-Efficiency LLC Converter with Two Transformers for Wide Input-Voltage Range Applications. IEEE Trans. Power Electron. 2013, 28, 1946-1960. [CrossRef]

21. Lin, B.R.; Liu, Y.C. Analysis of a Wide Voltage Hybrid Soft Switching Converter. Electronics 2021, 10, 473. [CrossRef]

22. Lin, B.R.; Ko, M.C. Investigation of a hybrid converter with 16:1 wide voltage operation. IET Proc. Electron. Lett. 2021, 57, 74-77. [CrossRef] 